\title{
Impact of Social Media on Self-Esteem
}

\author{
Muqaddas Jan \\ IoBM, Pakistan \\ Sanobia Anwwer Soomro \\ Iqra University, Pakistan \\ Nawaz Ahmad \\ Assistant Professor at IoBM, Pakistan
}

doi: 10.19044/esj.2017.v13n23p329 URL:http://dx.doi.org/10.19044/esj.2017.v13n23p329

\begin{abstract}
Social media has gained immense popularity in the last decade and its power has left certain long-lasting effects on people. The upward comparisons made using social networking sites have caused people to have lower self-esteems. In order to test the hypothesis 150 students from institute of business management were surveyed through questionnaires and interviews. This research was limited to the students of IoBM and Facebook, being the most popular social networking site was used as the representative of social media. Correlation and regression model was applied to the data with the help of SPSS statistics to test the relationship between social media and self-esteem. The major findings suggest that approximately $88 \%$ people engage in making social comparisons on Facebook and out of the $88 \%, 98 \%$ of the comparisons are upward social comparisons. Further this research proves there that there is a strong relationship between social media and selfesteem. Increase in social media usage causes the self-esteem of individuals to decrease. One hour spent on Facebook daily results in a 5.574 decrease in the self-esteem score of an individual.
\end{abstract}

Keywords: Social media, Self-esteem and Social networking sites

\section{Introduction}

\subsection{Background}

Early 21 st century marked the emergence and growth of social networking sites in the whole world. Since then these sites have become a major part of people's lives, specially the lives of the youth. Many teenagers are using social media, especially Facebook, to build relationships, connect with the world, share and gain knowledge and information, build stronger personalities and have better social lives (Boyd, 2007). Mitchell (2002) 
claimed that social networking sites are used by youngsters to get engaged in romantic and casual online relationships. It has been observed by the changing behavior of the people that social media has many negative repercussions on people. Social networking sites help people to make social comparisons which increase the psychological distress of individuals and as a result lower the overall level of self-esteem (Chen \& Lee, 2013). Many observers and researchers believe that due to increase in the usage of social networking sites, people have become the victims of lower self-esteem and self-growth.

\subsection{Objectives}

The major objective of this research is to highlight a clear impact of Facebook; as a most popular and frequently used social media sight on the self-esteem of youngsters. A mix method approach adopted therein would further enhance our study design and would provide clear insight towards direction of such relationship. This study would divert the attention of individuals \& help them analyze their over indulgence on social media with in the most precious hours of their life and its possible consequences on lowering their social esteem.

\subsection{Scope of the Study}

Due to the constraints of time, money and geographical boundaries, this research was conducted in IOBM in Karachi, Pakistan. The sample size has also been limited to 150 participants due to time constraints. This research is narrow in scope and can be subject to limitations.

One of the inherent limitations of the study was that the respondents were not observed, they were given questionnaires to fill. So the results of the research depend upon the integrity and truthfulness of the subjects. Secondly all social networking sites were not included in the research. Only Facebook was considered the representative of all the social networking sites.

\subsection{Problem Statement}

High usage of social media is resulting in lower self-esteem amongst youth.

\subsection{Research Questions}

- Does any relationship exist between time spent on Facebook and selfesteem of individuals?

- What is the nature of such relationship?

- What factors of social media are responsible for lowering self-esteem of individuals?

- What solutions could be offered to solve this dilemma? 


\subsection{Hypothesis}

$\mathrm{H}_{0}$ : there is no relationship between social media and self esteem

$\mathrm{H}_{\mathrm{a}}$ : there is a relationship between social media and self esteem

\section{Literature Review:}

The use of social networking sites has globalized immensely in the past decade. Facebook is the most widely used social networking site as it has more than one billion users worldwide (Facebook, 2012). Apart from being the medium for expression of opinion and platform for sharing of knowledge and moments, Facebook has also reduced distances by making people feel more connected and helped them build new relationships and maintain the existing ones. (Boyd \& Ellison, 2007).

One major feature of Facebook is to make the personal profiles of users available for public or friends to view and scrutinize and allow them to pass on their judgments and give feedback through comments to make sure the user understands their opinion on his personal life (Muise et al., 2009; Boyd \& Ellison, 2007).

These opinions of other people, either friends or public, and the feedback from them have very strong effect on people's self-esteems. Heatherton and Polivy (1991) claim that the concept of self-esteem can be either stable or fluid in nature i.e. it can take time to develop for some people while it can change with trends and daily events for others. While negative feedback lowers the self-esteem of individuals, positive feedback increases the selfesteem to a very high degree (Valkenburg et al., 2006).

Some of the researchers have identified the major benefits and advantages of social networking sites. For example, Facebook gives individuals a sense of freedom and identity, boosts up the confidence level of individuals and cheers them up during hard times (Nyagah, Stephen and Muema, 2015). It also helps shy and introvert students, who find it difficult to initiate conversation, to build social capital as it reduces the level of restrictions involved in communication and offers a forum to build healthy and strong bonds and relationships (Ellison, Steinfield, \& Lampe, 2007). Amichai, Hamburger \& Vinitzky (2010) argue that many Introverts build relationships through social networking sites because usually they find difficulties during face to face dealings.

In order to fulfill their affiliation needs majority of the humans get possessed by an elementary drive which forces them to make social comparisons between themselves and others (Schachter, 1959). These affiliation needs are triggered by many social networking sites. Festinger (1954) claimed that these social networking sites lead many people to do self-evaluations and make social comparisons between themselves and others 
based on social classes, social roles, beauty, popularity, wealth accumulation and other social functions.

People engage in two types of comparisons on social networking sites, upward and downward comparison. The former one is the comparison between an individual and those superior from him and possessing positive attributes while the latter one marks the comparison between an individual and those inferior than him and possessing negative attributes (Wills, 1981; Wood, 1989). Lockwood and Kunda (1997) argue that upward social comparisons can be inspirational for people as they could focus on replicating their comparison targets behavior and attitudes. But it has also been observed that upward comparisons make people feel inferior and have negative evaluations of themselves (Morse \& Gergen, 1970). As a result, these upward comparisons in most of the cases have a negative effect on the self-esteems of people (Vogel, Rose, Roberts and Eckles, 2014).

Many researchers have concluded from there researches that high usage of Facebook causes depression and decreased prosperity in individuals (Feinstein et al., 2013). As most people do not use Facebook for their emotions or moods; they use Facebook to overcome their loneliness but only end being less satisfied with their lives (Kross et al., 2013). Chou and Edge (2012) concluded that people who use facebook frequently have a very firm belief that other users, who they don't know very well offline, are living a very healthy, happy and prosperous life than themselves. These assumptions about other peoples' lives cause depression amongst individuals. According to Pantic (2014) anxiety, depression, psychotic disorders and low self-esteem are all the likely results of social networking sites, especially Facebook. Chen \& lee (2013) argue that Facebook usage is directly related to psychological distress of individuals which as a result reduces the selfesteem of people. Facebook has also caused cyber bullying to increase as through Facebook rumors could be spread easily and indecent pictures of individuals without their consent could be uploaded. Anxiety, depression and low self-esteem are all symptoms and results of cyber bullying (Moreno \& Kolb, 2012).

Some researchers disagree with this and claim that generally it is just the internet which affects the self-esteem of individuals not the social networking sites specifically (Valkenburg, Peter and Schouten, 2006). Ellison et al (2007) found out that youngsters with low self-esteem find Facebook more beneficial as compared to the ones with high self-esteem. Due to the use of Facebook people with low self-esteems possess more social capital than the ones with high self-esteems (Tazghini \& Siedlecki, 2013). 


\section{Methodology:}

\subsection{Data}

Primary data was collected for this research. Questionnaires were distributed and filled out by the participants of the sample which asked some basic questions about their attachment with and time spent on social networking sites. Certain interviews were also conducted to know how people view other people's profiles and whether they make comparisons or not. Apart from this, Rosenberg self-esteem scale (Rosenberg, 1965) was used to identify the level of self-esteem of the participants. Questionnaire is given in the appendix 1 at the end of the report. In order to quantify the data level of satisfaction of the respondents was measured on a likert scale of 1-4. The division of points is mentioned in appendix 2 .

\subsection{Variables}

The independent variable in this study is the social media usage of people. Computer mediated communication, such as Facebook has gained millions and millions of users in the past decade and now it has proven to be "one of the most trafficked site in the world" (Facebook, 2011a).

The dependant variable is the self-esteem of people which is affected by social functions. Self-esteem is both stable and fluid, it develops and changes with time and is affected by daily events (Heatherton and Polivy, 1991).

\subsection{Inclusion criteria}

As youngsters tend to use social networking sites more than adults, this research will be based on youngsters of both genders between the age group of 18 and 25. Instead of complicating the research with different social networking sites, the main focus of the study would be to find the effect of Facebook usage on self-esteem.

\subsection{Sample and Sampling Techniques}

As the research is non-probabilistic and due to the geographical boundaries convenience sampling will be used.

A sample of 150 youngsters was selected, with $95 \%$ confidence level and confidence interval of 8 , between the age of 18 and 25 . They were given the questionnaires to fill.

\subsection{Statistical Model}

- $\quad$ Comparison of means

- $\quad$ Correlation between times spent on Facebook and self esteem

- Regression analysis between times spent on Facebook and self esteem 


\section{Results and Discussion:}

\subsection{Descriptive Analysis}

Sample of 150 students from IoBM was selected based on the confidence level of $95 \%$ and confidence interval of 8 . In order to test the hypothesis each respondent was given a questionnaire which tested their selfesteem and enquired the amount of time they spent on Facebook.

Summary Report

Table 1 Self-esteem

\begin{tabular}{cccc}
\hline Time spent on facebook & Mean & $\mathrm{N}$ & Std. Deviation \\
\hline less than half an hour & 25.2500 & 32 & 2.67606 \\
\hline 1-3 hours & 16.7358 & 53 & 1.07687 \\
\hline 3-5 hours & 12.1951 & 41 & 1.32702 \\
\hline more than 5 hours & 8.2500 & 24 & 2.11105 \\
\hline Total & 15.9533 & 150 & 5.93967
\end{tabular}

The summary of the data is mentioned below in table 1 . According to the survey the people who spend less than half an hour daily on Facebook have a mean score of 25.25 for self-esteem; people who spend 1-3 hours daily on Facebook have a mean score of 16.7358 for self-esteem; people who spend 3-5 hours daily on Facebook have a mean score of 12.1951 for selfesteem; people who spend more than 5 hours daily on Facebook have a mean score of 8.25 for self-esteem.

\subsection{Inferential Analysis}

Correlation test was applied to the data mentioned in table 1 to find out whether there is any relationship between self-esteem and time spent on Facebook. The results of the correlation test are summarized in table 2.

Table 2

Correlations

Time spent on Self-esteem facebook

\begin{tabular}{|c|c|c|c|}
\hline \multirow{4}{*}{ Time spent on facebook } & & & \\
\hline & Pearson Correlation & 1 & $-.933^{* *}$ \\
\hline & Sig. (2-tailed) & & .000 \\
\hline & $\mathrm{N}$ & 150 & 150 \\
\hline \multirow{3}{*}{ Self-esteem } & Pearson Correlation & $-.933^{* *}$ & 1 \\
\hline & Sig. (2-tailed) & .000 & \\
\hline & $\mathrm{N}$ & 150 & 150 \\
\hline
\end{tabular}

**. Correlation is significant at the 0.01 level (2-tailed).

From the result of the correlation test it can be concluded that there is a negative relationship between the two variables. Increase in the time spent on Facebook would result in the decrease of the self-esteem of an individual. It can also be concluded that there is a statistically significant correlation between social media usage and self-esteem as the sig value shown in table 2 is less than 0.05 . 
After applying the correlation test the next step was to apply linear regression analysis to predict the value of the dependent variable (selfesteem) with the help of the predictor variable (time spent on Facebook). The summary of the results are mentioned in table 4, 5 and 6.

Table 3

\section{Model Summary}

\begin{tabular}{ccccc}
\hline Model & $\mathrm{R}$ & R Square & $\begin{array}{c}\text { Adjusted R } \\
\text { Square }\end{array}$ & $\begin{array}{c}\text { Std. Error of the } \\
\text { Estimate }\end{array}$ \\
\hline 1 & $.933^{\mathrm{a}}$ & .871 & .870 & 2.14059 \\
\hline
\end{tabular}

a. Predictors: (Constant), Time spent on facebook

Table 3 shows the model summary of the data. The value of $\mathrm{R}$ is 0.933 and it represents simple correlation which we have already calculated in table 2. The R Square shows how much of total variation in the self -esteem (dependent variable) can be explained by time spent on Facebook (independent variable) which is very large in this case; $87.1 \%$.

Table 4

ANOVA $^{\mathrm{a}}$

\begin{tabular}{ccccccc}
\hline & Model & Sum of Squares & df & Mean Square & F & Sig. \\
\hline \multirow{3}{*}{1} & Regression & 4578.522 & 1 & 4578.522 & 999.218 & $.000^{\text {b }}$ \\
\cline { 2 - 7 } & Residual & 678.152 & 148 & 4.582 & & \\
\cline { 2 - 7 } & Total & 5256.673 & 149 & & \\
\hline \multicolumn{7}{c}{ a. Dependent Variable: Self-esteem } \\
\hline
\end{tabular}

b. Predictors: (Constant), Time spent on facebook

ANOVA Table helps to measure how well the regression equation fits the data. As shown in table 4 sig, value is less than 0.05 . This means that the regression model is statistically significant and a good predictor of the dependent variable which in this case is the self-esteem of individuals.

Table 5

Coefficients $^{\mathrm{a}}$

\begin{tabular}{ccccccc}
\hline Model & \multicolumn{2}{c}{$\begin{array}{c}\text { Unstandardized } \\
\text { Coefficients }\end{array}$} & \multicolumn{2}{c}{$\begin{array}{c}\text { Standardized } \\
\text { Coefficients }\end{array}$} & \multirow{2}{*}{ T } & \multirow{2}{*}{ Sig. } \\
\cline { 2 - 5 } & $\mathrm{B}$ & Std. Error & Beta & & \\
\hline (Constant) & 29.221 & .455 & & 64.271 & .000 \\
\hline Time spent on facebook & -5.574 & .176 & -.933 & - & -31.610 & .000 \\
\hline
\end{tabular}

a. Dependent Variable: Self-esteem

Table 5, the coefficients table, helps to make predictions of the dependent variable by using the regression equation. The regression equation is made with the help of beta values and after putting the value of independent variable, time spent on Facebook, will predict the value of the dependent variable, self-esteem. The regression equation of this research is:

$$
\text { Self-esteem=29.221-5.574(time spent on Facebook) }
$$




\subsection{Discussion}

The first section of the questionnaire enquired how frequently Facebook is used by each respondent on a daily basis, the reason behind the usage and whether these respondents make comparisons with others on Facebook or not. The second section of the questionnaire measured the self-esteem of each individual.

After the questionnaires were collected certain interviews were conducted and people were asked the reason for which they use Facebook and whether they make social comparisons on Facebook or not. According to the results approximately $88 \%$ people engage in making social comparisons on Facebook and out of the $88 \%, 98 \%$ of the comparisons are upward social comparisons. It has been observed that upward comparisons make people feel inferior and have negative evaluations of themselves (Morse \& Gergen, 1970). These upward comparisons in most of the cases have a negative effect on the self-esteem of people (Vogel, Rose, Roberts and Eckles, 2014). The answers of the respondents suggested that every individual between the age of 18 and 25 uses Facebook and most of the people use Facebook to build new relationships, remain informed regarding the major events in the world and fulfill their affiliation needs. Numerous studies have proved that social networking sites are used by teenagers to make strong and healthy relationships with their peers (Ellison, Steinfield, \& Lampe, 2007).

The results of the questionnaire were compiled and analyzed. The findings of this research suggest that there is a strong relationship between social media usage and self-esteem of individuals. Both of these variables are negatively associated as shown in table 2 . Increase in social media usage would cause the self-esteem of people to decrease. Time spent on Facebook could be used to predict the self-esteem of individuals. One hour spent on Facebook daily results in a 5.574 decrease in the self-esteem score of an individual.

This research clearly shows the negative impact of Facebook on the selfesteem of individuals. Self-esteem is the mixture of two variables; the selfrespect of individuals and their self-confidence (Branden, 1969). As people spend more time on Facebook, they visit other people's profiles and they start envying certain individuals who they think are superior or better-off than them. Walther and colleagues argue that most people use Facebook to know what is going on in other people's lives and judge others on the basis of the cues found on the profiles of these people e (Walther, Van Der Heide, Kim, Westerman, \& Tong, 2008). These individuals make upward comparisons with others. As a result they start feeling inferior, less privileged and ungrateful. These negative feelings have a direct impact on the self-esteem of individuals. Social comparisons made using social networking sites such as Facebook makes the people feel worse about their 
lives and promotes negative well-being of individuals (Steers, Wickham, \& Acitelli, 2014). As a result people end up having low self-evaluations.

\section{Conclusion, Limitations, and Recommendations:}

\subsection{Conclusion}

Social media has a very strong impact on the self-esteem of individuals. Students use these social networking sites for information, communication and building and maintain of relationships. But majority of the people end up making upward and downward comparisons with others. The upward comparisons make people envy others and their lifestyles and also feel less obliged and ungrateful for their bounties. As a result the self-esteem of such people gets negatively affected. Social media is growing very drastically in almost every country in the world. So it is impossible to keep people, especially students who use Facebook on a daily basis, away from social media for a very long time. Parents and teachers should play an active role here by guiding students regarding self-esteem, self-recognition, selfactualization and self-confidence. Parents should also limit the access of their children on these sites plus raise awareness in their children regarding the negative repercussions of Facebook.

\subsection{Limitations}

As this was a small research conducted for academic purposes it was limited to the students of IoBM. The sampling method used was convenience sampling so there can be certain doubts on whether the sample is a true representation of the whole population or not. Due to certain cost and time constraints the sample size was also kept short. Though the questionnaire was well constructed but the integrity of the students cannot be measured. Self-esteem depends on person to person and the factors that cause to change also vary from person to person so their never can be an accurate measure for self-esteem. Due to embarrassment or other social factors the respondents might have not been truthful in their answers. Instead of including each social networking site in the research only Facebook was used and considered the representation of all the social networking sites.

\subsection{Recommendations}

- Parents should keep a check on their children. They should observe the effects of these sites on their children and accordingly limit the time their children spend on such social networking sites.

- Children should be taken to workshops and awareness programs where they should be guided about self-esteem, self-recognition, selfactualization and self-confidence. 
- Parents and teachers should raise the morale of students and make them more confident in their conduct.

- Campaigns must be held to raise awareness in people regarding the negative repercussions of social networking sites.

\section{References:}

1. Amichai-Hamburger, Y. \& Vinitzky, G. (2010). Social network use and personality. Computers in Human Behavior, 26, 1289-1295.

2. Boyd, D. M., \& Ellison, N. B. (2007). Social network sites: Definition, history, and scholarship. Journal of Computer-Mediated Communication, 13, 210-230.

3. Branden, N. (2001). The psychology of self-esteem.1st Ed 110. San Francisco: Jossey-Bass

4. Chen, W. \& Lee, K. (2013). Sharing, liking, commenting, and distressed? The pathway between Facebook interaction and psychological distress. Cyberpsychology, Behavior, and Social Networking, 16(10), 728-734.

5. Chou, H.-T. G., \& Edge, N. (2012). "They are happier and having better lives than I am": The impact of using Facebook on perceptions of others' lives. Cyberpsychology, Behavior, and Social Networking, 15, 117-121.

6. Ellison, N., Steinfield, C., \& Lampe, C. (2007). The benefits of Facebook "friends:" social capital and college students' use of online social network sites. Journal of Computer-Mediated Communication, 12, 1143-1168.

7. Facebook. (2011a, April 28). Facebook factsheet.

8. Facebook. (2012). Statistics. Facebook.com.

9. Feinstein, B. A., Hershenberg, R., Bhatia, V., Latack, J. A., Meuwly, N., \& Davila, J. (2013). Negative social comparison on Facebook and depressive symptoms: Rumination as a mechanism. Psychology of Popular Media Culture, 2, 161-170.

10. Festinger, L. (1954). A theory of social comparison processes. Human Relations, 7, 117-140.

11. Heatherton, T. F., \& Polivy, J. (1991). Development and validation of a scale for measuring self esteem. Journal of Personality and Social Psychology, 60, 895-910.

12. Ivcevic, Z., \& Ambady, N. (2012). Personality impressions from identity claims on Facebook. Psychology of Popular Media Culture, 1, 38-45.

13. Kalpidou, M., Costin, D., \& Morris, J. (2011). The relationship between Facebook and the well-being of undergraduate college 
students. Cyberpsychology, Behavior, and Social Networking, 14, 183-189.

14. Kross, E., Verduyn, P., Demiralp, E., Park, J., Seungjae Lee, D., Lin, N,...Ybarra, O. (2013). Facebook use predicts declines in subjective well-being in young adults. PLoS One, 8, e69841.

15. Lockwood, P., \& Kunda, Z. (1997). Superstars and me: Predicting the impact of role models on the self. Journal of Personality and Social Psychology, 73, 91-103.

16. Marsh, H. W., \& Parker, J. W. (1984). Determinants of student selfconcept: Is it better to be a relatively large fish in a small pond even if you don't learn to swim as well? Journal of Personality and Social Psychology, 47, 213-231.

17. Mehdizadeh, S. (2010). Self-presentation 2.0: Narcissism and selfesteem on Facebook. Cyberpsychology, Behavior, and Social Networking, 13, 357-364.

18. Moreno, M., \& Kolb, J. (2012). Social networking sites and adolescent health. Pediatric Clinics of North America, 59(3), 601612.

19. Morse, S., \& Gergen, K. J. (1970). Social comparison, selfconsistency, and the concept of self. Journal of Personality and Social Psychology, 16, 148-156.

20. Muise, A., Christofides, E., \& Desmerais, S. (2009). More information than you ever wanted: Does Facebook bring out the green-eyed monster of jealousy? CyberPsychology \& Behavior, 12(4), 441- 444.

21. Nadkarni, A., \& Hofmann, S. G. (2012). Why do people use Facebook? Personality and Individual Differences, 52, 243-249.

22. Pantic, I. (2014). Online social networking and mental health. Cyberpsychology, Behavior, and Social Networking, X(X), 1-6.

23. Pyszczynski, T., Greenberg, J., \& LaPrelle, J. (1985). Social comparison after success and failure: Biased search for information consistent with a self-serving conclusion. Journal of Experimental Social Psychology, 21, 195-211.

24. Rosenberg, M. (1965). Society and the adolescent self-image. Princeton, NJ: Princeton University Press.

25. Rutledge, C. M., Gillmor, K. L., \& Gillen, M. M. (2013). Does this profile picture make me look fat? Facebook and body image in college students. Psychology of Popular Media Culture, 2, 251-258.

26. Schachter, S. (1959). The psychology of affiliation: Experimental studies of the sources of gregariousness, 1. Stanford, CA: Stanford University Press. 
27. Steers, M., Wickham, R., \& Acitelli, L. (2014). Seeing everyone else's highlight reels: how Facebook usage is linked to depressive symptoms. Journal of Social and Clinical Psychology, 33(8), 701731.

28. Tazghini, S. \& Siedlecki, K. (2013). A mixed approach to examining Facebook use and its relationship to self-esteem. Computers in Human Behavior, 29, 827-832.

29. Tosun, L. P. (2012). Motives for Facebook use and expressing the "true self" on the Internet. Computers in Human Behavior, 28, 1510 1517.

30. Valkenburg, P. M., Peter, J., \& Schouten, M. A. (2006). Friend networking sites and their relationship to adolescents' well-being and social selfesteem. Cyber Psychology \& Behavior, 9, $584-590$.

31. Vogel, E., Rose, J. P., Roberts, L. R., \& Eckles, K. (2014). Social comparison, social media, and self-esteem. Journal of Educational Policy and Entrepreneurial Research, 2(1), 87-92.

32. Walther, J.B., Van Der Heide, B., Kim, S.Y., Westerman, D., \& Tong, S.T. (2008). The role of friends' appearance and behavior on evaluations of individuals on facebook: Are we known by the company we keep? Human Communication Research, 34, 28-49.

33. Wills, T. A. (1981). Downward comparison principles in social psychology. Psychological Bulletin, 90, 245-271.

34. Wood, J. V. (1989). Theory and research concerning social comparison of personal attributes. Psychological Bulletin, 106, 231248. 


\section{Appendix A: Questionnaire}

1) How much do you spend on Facebook?

\begin{tabular}{|l|l|l|l|}
\hline Half an hour & $1-3$ hours & $3-5$ hours & More than 5 hours \\
\hline
\end{tabular}

2) How often do you comment on other people's profile?

\begin{tabular}{|l|l|l|l|l|}
\hline Daily & Weekly & Monthly & Yearly & Never \\
\hline
\end{tabular}

3) While viewing other people's profile do you compare yourself with them?

\begin{tabular}{|l|l|l|}
\hline Yes & No & Sometimes \\
\hline
\end{tabular}

4) Does the number of likes on your picture or status affect you?

\begin{tabular}{|l|l|l|}
\hline Yes & No & Sometimes \\
\hline
\end{tabular}

5) Why do you use Facebook?

\begin{tabular}{|l|l|l|l|l|}
\hline $\begin{array}{l}\text { Building } \\
\text { relationships }\end{array}$ & $\begin{array}{l}\text { Medium of } \\
\text { communication }\end{array}$ & $\begin{array}{l}\text { Information } \\
\text { affiliation } \\
\text { needs }\end{array}$ & $\begin{array}{l}\text { Other(please } \\
\text { specify) }\end{array}$ \\
\hline
\end{tabular}

Instructions: Below is a list of statements dealing with your general feelings about yourself. Please indicate the level of your satisfaction on a scale of 1-4 with 4 being the highest level of satisfaction.

\begin{tabular}{|l|l|l|l|l|}
\hline & 1 & 2 & 3 & 4 \\
\hline 1. On the whole, I am satisfied with myself. & & & & \\
\hline 2. At times I think I am no good at all. & & & & \\
\hline 3. I feel that I have a number of good qualities. & & & & \\
\hline 4. I am able to do things as well as most other people. & & & & \\
\hline 5. I feel I do not have much to be proud of. & & & & \\
\hline 6. I certainly feel useless at times. & & & & \\
\hline $\begin{array}{l}\text { 7. I feel that I'm a person of worth, at least on an equal plane } \\
\text { with others. }\end{array}$ & & & & \\
\hline 8. I wish I could have more respect for myself. & & & & \\
\hline 9. All in all, I am inclined to feel that I am a failure. & & & & \\
\hline 10. I take a positive attitude toward myself. & & & & \\
\hline
\end{tabular}

